\title{
CARACTERIZAÇÃO QUANTO À CORROSÃO DE FILMES HÍBRIDOS POR SVET*
}

\author{
Caroline Antunes Corrêa ${ }^{1}$ \\ Matias de Angelis Korb² \\ Sandra Raquel Kunst ${ }^{3}$ \\ Célia de Fraga Malfatti ${ }^{4}$
}

\section{Resumo}

Filmes híbridos estão sendo utilizados como revestimentos de substratos metálicos para proteção contra corrosão. Este trabalho tem como objetivo verificar o comportamento corrosivo de filmes híbridos com diferentes concentrações de polietilenoglicol (PEG) sobre folhas de flandres pela técnica de varredura por eletrodo vibratório (SVET). Os resultados demonstraram que o aumento da concentração de polietilenoglicol ocasionou a formação de fissuras e delaminação do filme híbrido. As análises por SVET demonstraram a possibilidade de analisar a corrosão localizada em regiões com defeitos no filme e no substrato metálico.

Palavras-chave: Filmes híbridos; Corrosão; SVET.

\section{Abstract}

\section{CORROSION CHARACTERIZATION OF HYBRID FILMS BY SVET}

Hybrid films have been used as coatings for metallic substrate for corrosion protection. The present work aims to verify the behavior of hybrid coatings with different concentrations of polyethylenoglycol on tinplate for corrosion technique of vibrating electrode (SVET). The results showed that increasing of the polyethylenoglycol concentration caused the formation of cracks and delamination of the hybrid film. The analysis by SVET demonstrated the possibility of analyzing the localized corrosion in zones with defects in film and metallic substrate.

Keywords: Hybrid films; Corrosion; SVET.

1 Engenharia Metalúrgica, Graduanda, Estudante, Departamento de Metalurgia, Universidade Federal do Rio Grande do Sul, Porto Alegre, Rio Grande do Sul, Brasil.

2 Engenharia Metalúrgica, Doutorando em Engenharia de Minas, Metalúrgica e Materiais, Estudante, Departamento de Metalurgia, Universidade Federal do Rio Grande do Sul, Porto Alegre, Rio Grande do Sul, Brasil.

3 Engenharia Química Industrial, Doutora em Engenharia de Minas, Metalúrgica e de Materiais, Professora, Centro de Ciências Exatas e Tecnológica, Universidade de Caxias do Sul, Caxias do Sul, Rio Grande do Sul, Brasil.

4 Engenharia Metalúrgica, Doutora em Engenharia de Minas, Metalúrgica e de Materiais, Professora, Departamento de Metalurgia, Universidade Federal do Rio Grande do Sul, Porto Alegre, Rio Grande do Sul, Brasil. 


\section{INTRODUÇÃO}

O aço estanhado, conhecido como folha de flandres, vem sendo utilizado principalmente pela indústria alimentícia para embalagens metálicas, por apresentar boa plasticidade combinada com resistência mecânica. Contudo, existem problemas significativos relacionados com 0 uso de latas de folha de flandres para armazenamento de produtos alimentares, os quais podem apresentar comportamento corrosivo, levando a falhas de corrosão, perda da integridade do selante e problemas de descoloração do material metálico. Além disso, o estanho presente na embalagem pode ocasionar problemas de intoxicação alimentar [1]. Portanto, tratamentos superficiais estão sendo propostos para contornar estes problemas.

Entre os revestimentos estudados, os filmes híbridos (orgânico - inorgânico) obtidos pelo processo de sol-gel são mais comuns que filmes óxidos (inorgânicos) em termos de proteção à corrosão de substratos metálicos por duas razões. Primeiro, filmes híbridos podem formar revestimentos espessos (micrométricos) sem fissuras e com temperaturas de cura muito menores $\left(<100{ }^{\circ} \mathrm{C}\right)$ que temperaturas para sinterização dos óxidos $\left(400-800{ }^{\circ} \mathrm{C}\right)$. Segundo, o sistema hibrido tem maior flexibilidade para a utilização de aditivos anticorrosivos [2]. Para a caracterização quanto ao comportamento à corrosão, comumente são utilizadas técnicas eletroquímicas que apresentam informações sobre a corrente e o potencial do eletrodo de trabalho em uma célula eletroquímica. Estes valores de corrente e potencial são relativos à área total da amostra e não dão informações sobre a distribuição ao longo da superfície. Isto é particularmente importante para os casos de corrosão localizada como em corrosão por pites, intergranular, intersticial ou corrosão galvânica. A técnica de varredura por eletrodo vibratório (SVET) permite conhecer intensidades de correntes locais em superfícies metálicas ativas imersas em um eletrólito [3-5].

O objetivo deste trabalho é a caracterização quanto à corrosão de folhas de flandres revestidas com filmes híbridos com diferentes concentrações de polietilenoglicol (PEG) através da técnica de SVET.

\section{MATERIAIS E MÉTODOS}

\subsection{Preparação do Substrato e Obtenção do Revestimento Híbrido}

O material utilizado neste trabalho como substrato foi o aço estanhado, folhas de flandres, cuja composição química está descrita na tabela 1. Primeiramente, as folhas de flandres foram lavadas com acetona e secas com ar quente. Posteriormente, foram desengraxadas com detergente neutro, à $70^{\circ} \mathrm{C}$ por imersão por 10 minutos.

Para a caracterização quanto à corrosão, as amostras foram cortadas em uma dimensão de $7 \times 7 \mathrm{~mm}$ e fixadas em resina. A área analisada foi isolada com cera de abelha e colofônio.

Tabela 1. Composição química do aço estanhado

\begin{tabular}{cccccccc}
\hline Elemento & $\mathbf{C}_{\text {máx. }}$ & $\mathbf{M n}_{\text {máx. }}$ & $\mathbf{P}_{\text {máx. }}$ & $\mathbf{S}_{\text {máx. }}$ & $\mathbf{S i}_{\text {máx. }}$ & $\mathbf{A l}$ & $\mathbf{N}_{\text {máx. }}$ \\
\hline$\%$ & 0,06 & 0,2 & 0,02 & 0,02 & 0,02 & $0,02-$ & 0,005 \\
& & & & & & 0,06 & \\
\hline
\end{tabular}


O filme híbrido foi obtido a partir dos precursores alcoóxidos (TMSPMA) 3(trimetoxisililpropil) metacrilato $\left(\mathrm{C}_{10} \mathrm{H}_{20} \mathrm{SiO} 5\right)$ e (TEOS) Tetraetoxisilano $\left(\mathrm{C}_{8} \mathrm{H}_{20} \mathrm{SiO}_{4}\right)$ com adição de nitrato de cério, como inibidor, na concentração de 0,01M. Como solventes foram utilizados água deionizada e álcool. Após, foi adicionado o PEG 1500 na formulação do sol com diferentes concentrações $\left(20\right.$ e 60 g.L $\left.{ }^{-1}\right)$. O tempo de hidrólise foi de 24 horas.

A obtenção do filme híbrido sobre o substrato metálico foi através da técnica de dipcoating, utilizando os seguintes parâmetros operacionais: velocidade de retirada de $10 \mathrm{~cm} \cdot \mathrm{min}^{-1}$ e tempo de imersão do substrato metálico na solução híbrida de 5 min.

Após o processo de dip-coating, os substratos pré-tratados com os filmes híbridos foram curados a uma temperatura de $60^{\circ} \mathrm{C}$ por 20 minutos em estufa. A figura 1 apresenta o esquemático do processo.

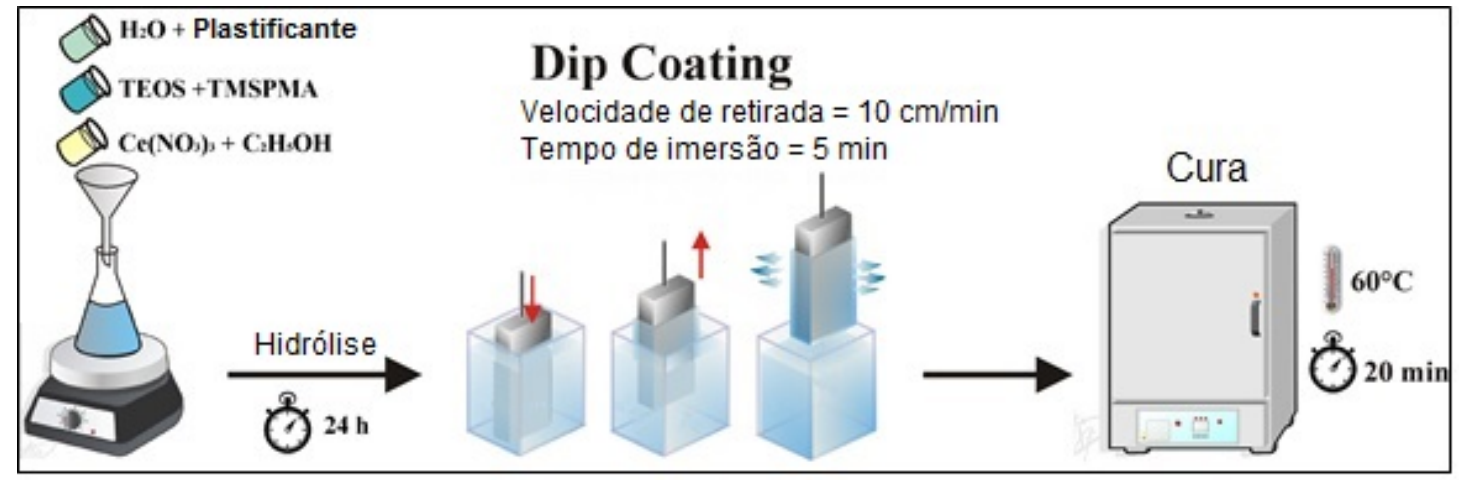

Figura 1. Esquema ilustrativo do processo.

A tabela 2 apresenta a nomenclatura adotada para a identificação das amostras elaboradas.

Tabela 2. Nomenclatura adotada para descrever as amostras

\begin{tabular}{cc}
\hline Amostra & Descrição \\
\hline TR & Folhas de flandres sem revestimento. \\
\hline TP20 & $\begin{array}{c}\text { Folha de flandres revestida com filme híbrido com } 20 \mathrm{~g} . \mathrm{L}^{-1} \text { de PEG, } \\
\text { curado à } 60^{\circ} \mathrm{C} \text { por } 20 \text { minutos, e com aplicação de monocamada. }\end{array}$ \\
\hline TP60 & $\begin{array}{l}\text { Folha de flandres revestida com filme híbrido com } 60 \mathrm{~g} . \mathrm{L}^{-1} \text { de PEG, } \\
\text { curado à } 60^{\circ} \mathrm{C} \text { por } 20 \text { minutos, e com aplicação de monocamada. }\end{array}$ \\
\hline
\end{tabular}

\subsection{Caracterização dos Filmes}

Os revestimentos foram caracterizados quanto à morfologia em microscópio eletrônico de varredura (MEV) JEOL 6060, operando com $20 \mathrm{kV}$. Quanto ao comportamento à corrosão, os revestimentos foram caracterizados utilizando a técnica de varredura por eletrodo vibratório (SVET) em um equipamento com sistema SVET/SIET da Applicable Electronics. Os testes de corrosão foram realizados por imersão em meio salino $(0,05 \mathrm{M}$ de $\mathrm{NaCl})$ por $24 \mathrm{~h}$ e $120 \mathrm{~h}$.

\section{RESULTADOS E DISCUSSÃO}

A Figura 2 mostra as micrografias obtidas por microscopia eletrônica de varredura para os filmes híbridos estudados, TP20 e TP60, antes do ensaio eletroquímico. É possível observar que o filme obtido com concentração de 20 g.L $\mathrm{L}^{-1}$ de PEG apresentou-se homogêneo e sem fissuras (Figura 2a). Enquanto o filme com uma maior adição de PEG, concentração de $60 \mathrm{~g} \cdot \mathrm{L}^{-1}$, apresentou fissuras na sua 
formação (Figura 2b). Isso pode ser devido à adição excessiva de plastificante, o qual interfere na reação de hidrólise do precursor alcóxido, formando ilhas densas de PEG e causando fissuras e delaminação no filme.

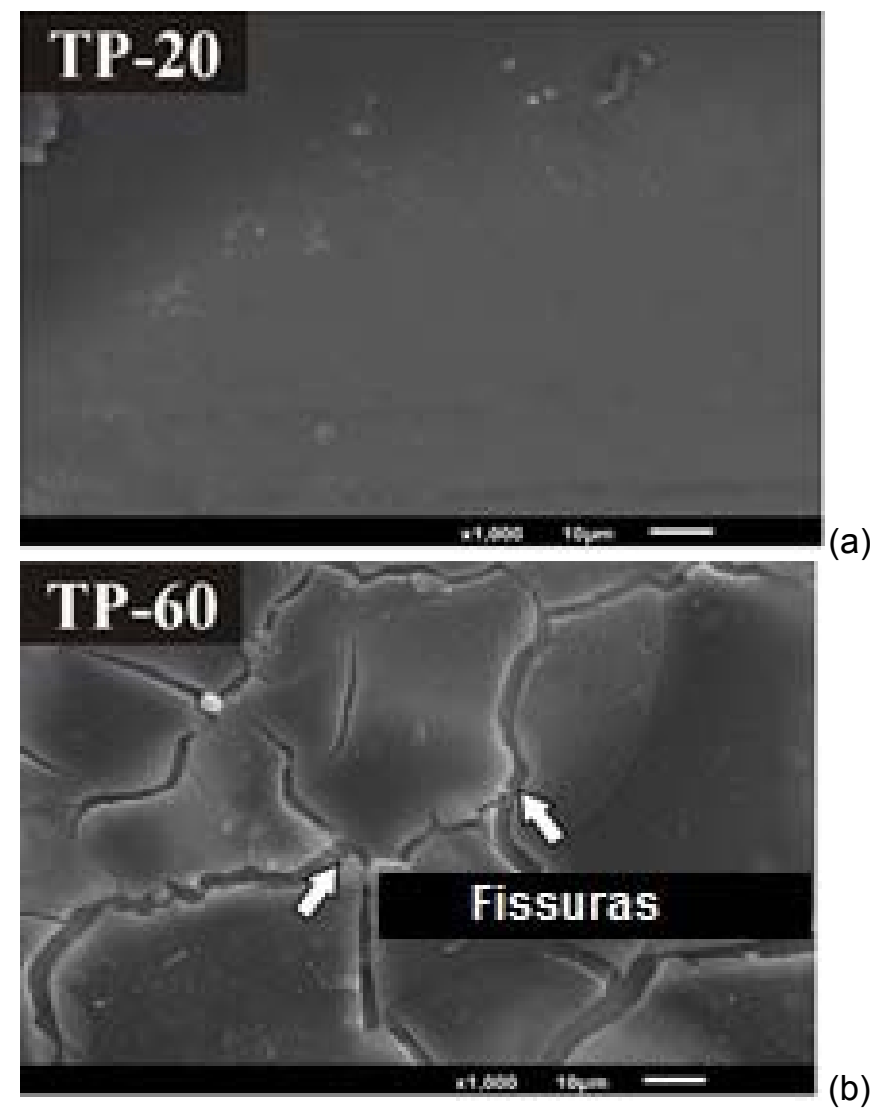

Figura 2. Micrografias da superfície do substrato metálico revestido com os filmes híbridos: a) TP20 b) TP60.

A Figura 3 e a Figura 4 apresentam os mapas superficiais das amostras obtidos através da técnica de SVET. É possível observar diferentes regiões localizadas sobre as superfícies das mesmas, as quais correspondem a áreas catódicas (região azul) e áreas anódicas (região vermelha). Para o substrato sem revestimento (TR) observou-se produtos de corrosão no tempo de $24 \mathrm{~h}$ (Figura 3), os quais são devidos ao ataque do eletrólito ao elemento ferro em zonas com porosidade e com defeitos do revestimento de estanho do aço estanhado [1]. Com o aumento do tempo de imersão, 120 h (Figura 4), a região anódica tende a se espalhar pela superfície do substrato metálico.

A amostra TP60, conforme observado por MEV (Figura 2b), apresentou fissuras e delaminação no filme híbrido o que ocasionou comportamento semelhante ao substrato sem revestimento (TR), regiões anódicas no período de $24 \mathrm{~h}$ (Figura 3) e espalhamento dessas após $120 \mathrm{~h}$ (Figura 4) de imersão.

O substrato metálico revestido com o filme híbrido com concentração de $20 \mathrm{~g} \cdot \mathrm{L}^{-1}$ de PEG (TP20) não apresentou produtos de corrosão no período de $24 \mathrm{~h}$ (Figura 3) e após $120 \mathrm{~h}$ (Figura 4) de imersão apresentou poucas regiões anódicas. Esse comportamento era esperado, pois o filme obtido sobre o aço estanhado foi homogêneo e sem fissuras (Figura 2a). 


\section{$24 \mathrm{~h}$}
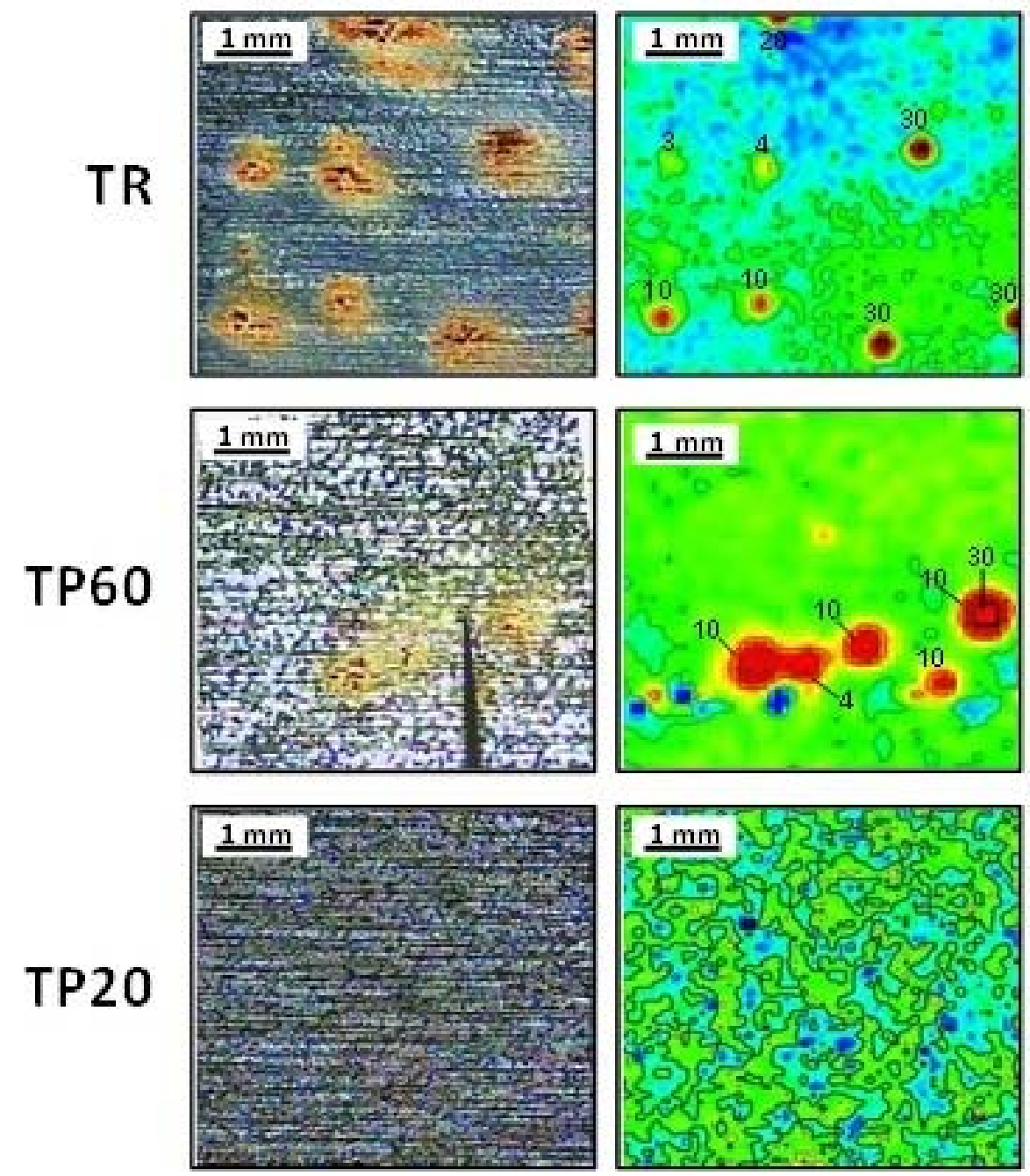

Figura 3. Mapas superficiais obtidos por SVET das amostras imersas em $0,05 \mathrm{NaCl}$ por $24 \mathrm{~h}$. 
$120 \mathrm{~h}$
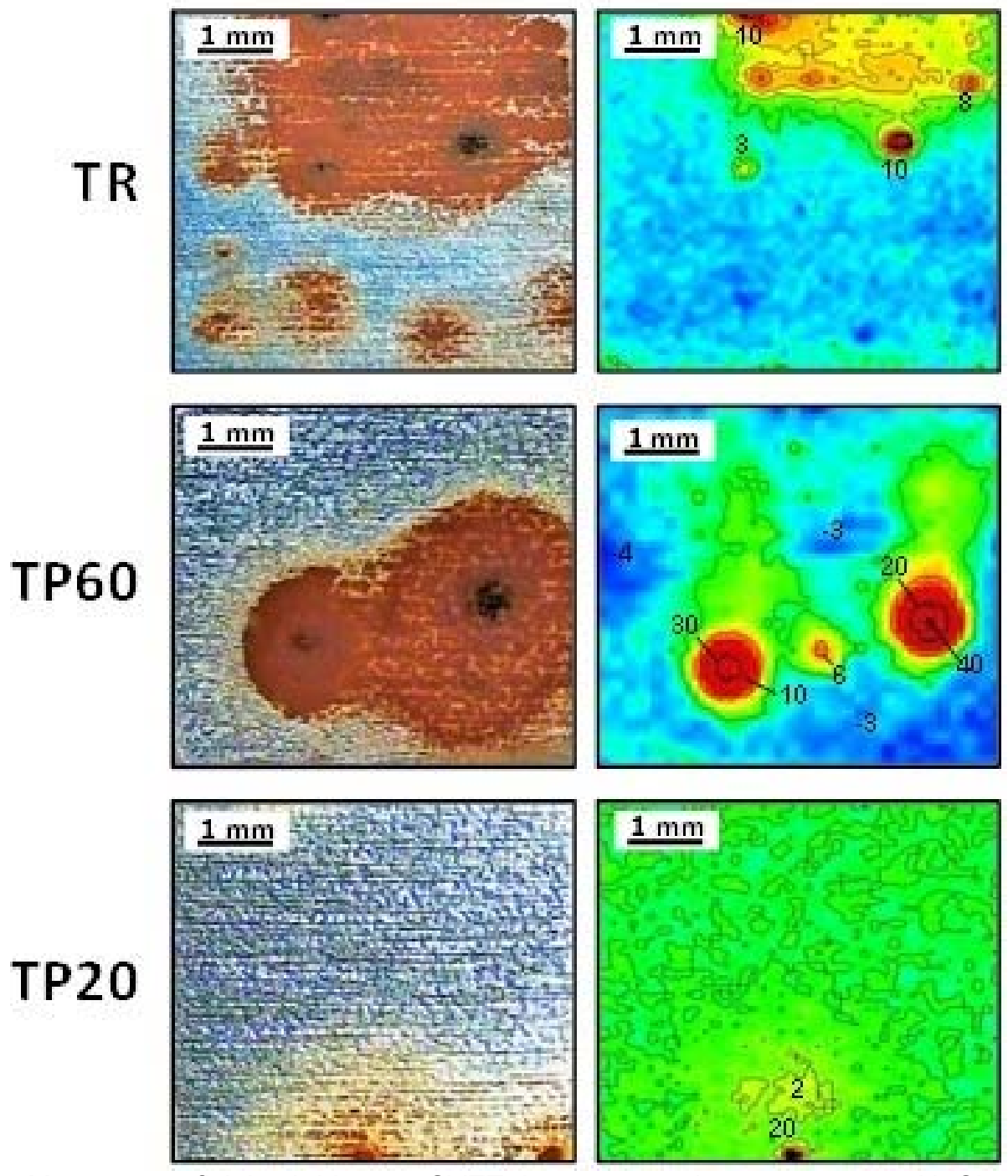

Figura 4. Mapas superficiais obtidos por SVET das amostras imersas em $0,05 \mathrm{NaCl}$ por $120 \mathrm{~h}$.

\section{CONCLUSÃO}

Filmes híbridos com diferentes concentrações de PEG foram obtidos sobre folhas de flandres através do processo de dip coating. Através da caracterização morfológica foi possível observar que o filme com maior concentração de PEG apresentou fissuras e delaminação sobre o substrato metálico.

A técnica eletroquímica de varredura por eletrodo vibratório (SVET) mostrou-se satisfatória para caracterização quanto à corrosão, pois foi possível distinguir as regiões atacadas através dos mapas de corrente, ou seja, regiões com porosidade e defeitos tanto do aço estanhado sem revestimento como dos filmes híbridos.

\section{Agradecimentos}

Os autores agradecem o apoio financeiro da Capes e do CNPq. 


\section{REFERÊNCIAS}

1 Xia DH, Song SZ, Wang JH, BI HC, Jiang YX, Han, ZW. Corrosion behavior of tinplate in $\mathrm{NaCl}$ solution. Trans. Nonferrous Met. Soc. China. 2012, 22: 717-724.

2 Wang D, Gordon PB. Sol-gel coatings on metals for corrosion protection. Progress in Organic Coatings. 2009, 64: 327-338.

3 Bastos AC, Simões AM, Ferreira MG. Corrosion of electrogalvanized steel in $0.1 \mathrm{M} \mathrm{NaCl}$ studied by SVET. Portugaliae Electrochimica Acta. 2003,21: 371-387.

4 Bastos AC, Dias SAS, Diamantino TC, Ferreira MGS. Uma introdução à técnica SVET. Corros. Prot. Mater. 2013, 32(2): 50-57.

5 Rodrigues JS. Estudo da corrosão de revestimentos de zinco - ligas obtidos por imersão a quente sobre aços baixo - carbono [dissertação de mestrado]. Porto Alegre: Universidade Federal do Rio Grande do Sul; 2011. 